\title{
Program Mitigasi Bencana Banjir dan Tanah Longsor Akibat Cuaca Ekstrim di Desa Sade Lombok Tengah NTB
}

\author{
Made Sutha Yadnya*1, L.A.S. Irfan Akbar ${ }^{2}$, Abdulah Zainuddin ${ }^{3}$, Bulkis Kanata ${ }^{4}$, \\ Teti Zubaidah ${ }^{5}$, Paniran $^{6}$ \\ ${ }^{1}$ Electrical Enginnering, PUI Geomagnetic Laboratory, the University of Mataram, Lombok, Indonesia. \\ ${ }^{13465}$ Jurusan Teknik Elektro, Fakultas Teknik Universitas Mataram, NTB, Indonesia
}

Article history

Received: 11-02-2021

Revised: 10-03-2021

Accepted: 15-03-2021

*Corresponding Author:

Made Sutha Yadnya,

Electrical Enginnering, PUI

Geomagnetic Laboratory, the

University of Mataram,

Lombok, Indonesia;

Email: msyadnya@unram.ac.id

\begin{abstract}
The condition of the situation in Sade Village is a hill, slope and mountainous area with and has a marble of more than 20 degrees, a thick layer of soil above the hillside, there is a poor water and land use system, resulting in flooding and landslides. The incident occurred in early 2021. This was carried out by a community service program to anticipate the possibility of floods and landslides due to extreme weather. This service was carried out by the Research Group on Electro Magnetic Technology and Environmental Conservation for Humanity. One of the missions related to the village community is towards Tangguh Bencana Village (DESTANA).
\end{abstract}

Keywords: extreme weather; flood; landslide

Abtrak: Kondisi situasi Desa Sade merupakan daerah bukit, lereng dan pegunungan dengan dan ada mempunyai kelereng lebih dari 20 derajat, lapisan lapisan tanah tebal diatas lereng perbukitan, terdapat sistem tata air dan tata guna lahan yang buruk, mengakibatkan kejadian banjir dan tanah longsong. kejadian terjadi pada awal tahun 2021. Hal tersebut dilaksanakan program pengabdian kepada masyarakat untuk mengantisipasi kemungkinan akan terjadinya bahaya banjir dan tanah longsor akibat cuaca ekstim. Pengabdian ini dilaksanakan kelompok riset Teknologi ElektroMagnetika dan Konservasi Lingkungan untuk Kemanusiaan. Salah satu misi yang berhubungan dengan masyarakat desa adalah menuju Desa Tangguh Bencana (DESTANA).

Kata Kunci: cuaca ekstrim; banjir; tanah longsor

\section{PENDAHULUAN}

Cuaca ekstrim yang merupakan dampak dari perubahan iklim memerlukan perhatian khusus untuk mempredikisi bahaya banjir dan tanah. Lombok yang diguncang gempa pada tahun 2018 banyak bangunan yang hacur terutama bangungan saluran air. Daya tampung sungai banyak berkurang akibat pendangkalan dan retak (Yadnya 2021).

Universitas Mataram memiliki obsevatorium di Rembitan bagian dari Pusat Unggulan Iptek (PUI) Geomagnetik mengukur magnet bumi dengan satuan magnet bumi nTesla (Nano Tesla). Hasil pengukuran terjadi anomali (penurunan nilai magnet bumi. Ini merupakan precursor akan terjadinya 
gempa. Desa Sade dan Rembitan merupakan satu kawasan yang menjadi satu kesatuan yang harus dijaga dan memberikan pengetahuan akan bahaya banjir dan tanah longsor akibat cuaca ekstrim. Hubungan yang baik dengan Kadus penanggung jawab di desa, aparat desa, serta pemuda dan pemudi merupakan kunci salah satu objek pelaksanan program pengabdian kepada masyarakat oleh kelompok riset Teknologi ElektroMagnetika dan Konservasi Lingkungan untuk Kemanusiaan. Salah satu misi yang berhubungan dengan masyarakat desa adalah menuju Desa Tangguh Bencara (DESTANA).

Badan Penanggulangan Bencana Daerah (BPBD) Nusa Tenggara Barat memberikan data bahwa terjadi banjir pada kondisi cuaca ekstrim di bulan Januari 2021 yang berdampak pada 350 keluarga di Kabupaten Lombok Tengah, termasuk Kawasan Ekonomi Khusus Mandalika (KEKM) serta daerah sekitarnya termasuk Desa wisata yaitu Desa Sade. Banjir dan tanah longsor merupakan becana cukup parah terdapat pada warga yang terdampak banjir tersebar di tiga kecamatan, yakni Kecamatan Praya Barat, Praya Barat Daya, dan Pujut. Posisi air yang sangat tinggi sampai 2 meter diperparah ada tanah longsor dan jembatan putus disertai jalan ambalas akirat gerusan air. Saat Air sudah mulai surut dan hujan sudah mereda. Para warga yang sebelumnya mengungsi ke tempat lebih aman seperti rumah makan dan masjid kini sudah kembali ke rumah masing-masing (BPBD, 2021). Universitas Mataram dalam melaksanakan pilar pengabdian kepada masyarakat telah mencanangkan bahwa pelestarian serta penangulangan terhadap bencana dilakukan secara berkesinambungan agar mempunyai sumbangsih sebagai civitas akademika yang memberikan kontribusi pada daerah, nasional sertta internasional.

Dalam situasi dan karakteristik tempat tertentu, efek dari gempa ini dapat diklasifikasikan dengan gempa dangkal. Ini bisa terjadi karena tanah di daerah yang dihantam gempa tersusun oleh endapan kuarter dengan sedimen lunakm sehingga gelombang gempa di permukaan tanah bertambah kuat. Secara umum, gempa bumi terjadi di lapisan litosfer yang dihuni lempeng-lempeng tektonik. Gempa dapat terjadi ini pada lempeng samudera mendesak turun ke mantel bumi dari batas lempeng konvergen, dan lempeng samudera yang padat bertabrakan dengan lempeng benua yang kurang padat (Zubaidah, 2014).

Dalam melakukan program pengabdian kepada masyarakat mengunakan hasil pelitian yang dilakukan pada tahun 2009 dan 2010 melalui Hibah Kompetensi. Penelitian tersebut meneliti kapasitas dan alira sungai alibat hujan. Pembelajaran dari alam yang memberikan data hujan, untuk penelitian pemodelan aliran diambil di seluruh dunia mengunakan komunikasi digital (digital image), maka peneliti mengajukan daerah Lombok (studi kasus Sungai Jangkuk) dan sekitarnya sebagai lokasi penelitian. Data pengukuran langsung dari curah hujan dengan posisi alat ukur yang dilakukan oleh data primer untuk mitigasi dan adaptasi terhadap bencana banjir. Letak geografis yang kental dengan unsur tropis maritime memiliki distribusi hujan yang pergerakan selnya menjadi tantangan utama dalam pembuatan model. Salah satu model pengukuran yang sudah pernah dilaksanakan meggunakan hasil penelitian pada tahun 2016 yaitu pengukiran besaran hujan yang dikonversi menjadi data dari distribusi hujan yang jatuh pada saat tertentu (Yadnya 2016).

Model yang didapat diharapkan mempunyai error yang sangat kecil untuk ketepatan control mitigasi dan adaptasi bahaya. Alat ukur ini digunakan untuk pengukuran suatu parameter. Parameterparameter ini diolah sehingga menghasilkan bentuk persamaan. Persamaan ini kemudian dikenal sebagai persamaan order (persaman model dengan variabel dan koeffisien yang dipergunakan) (Yadnya 2010). 

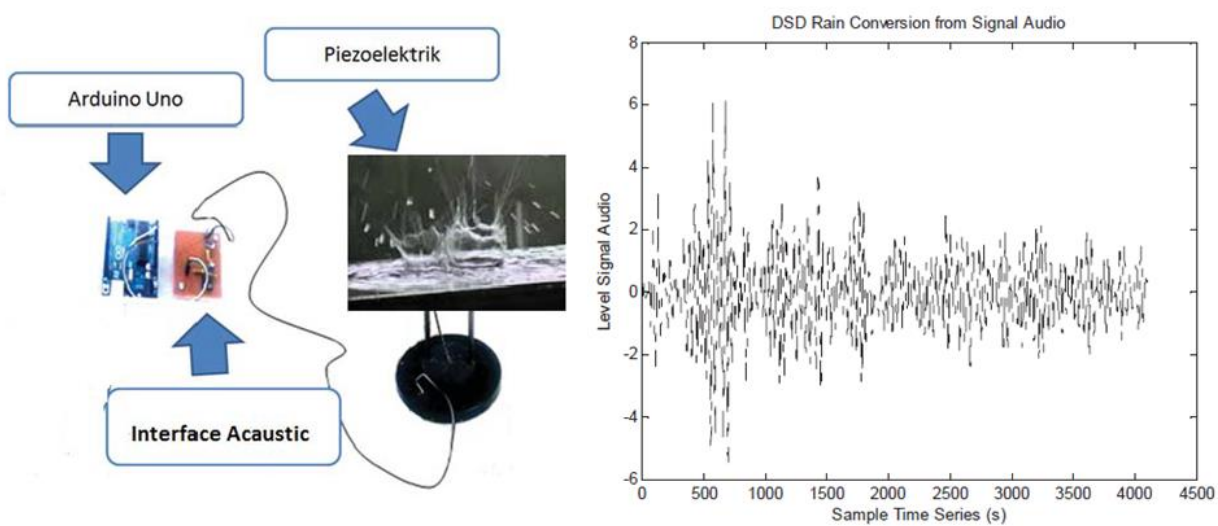

\section{METODE}

Pengukuran kapasitas daya tampung sungai terhadap air yang masuk, sebagai saluran air dari hulu ke hilir merupakan ketentuan yang seyogyanya di ketahui dalam kondisi normal, hal ini untuk dapat menegetahui daya tampung maksimal air yang mengalir di sungai. Proses terjadinya banjir apabila kondisi air yang masuk melewati kapasitas daya tampung sungai. Ini artinya air hujan yang masuk pada sungai mempunyai debit air. Sungai sebahgai saluran mendefinisikan debit yang merupakan jumlah air mengalir dalam saluran dinyatakan dengan ukuran liter per detik $\left(\mathrm{m}^{3} . / \mathrm{s}\right)$ Debit air saluran dapat diukur dengan cara langsung maupun secara tidak langsung.

Aliran air dikatakan memiliki sifat ideal dengan ketentuan bahwa air tersebut tidak dapat dimanfaatkan dan berpindah tanpa mengalami gesekan, hal ini berarti pada gerakan air tersebut memiliki kecepatan yang tetap pada masing-masing titik dalam pipa dan gerakannya beraturan akibat pengaruh gravitasi bumi. Suatu aliran dapat dipengaruhi oleh banyak faktor antara lain angin, besar kecilnya aliran, hujan, dan lain sebagainya.

Debit air dapat di hitung dengan rumus:

$\mathrm{Q}=\mathrm{A} \times \mathrm{V}$

Keterangan:

$\mathrm{V}=$ volume $\operatorname{air}\left(\mathrm{m}^{3}\right)$

$\mathrm{A}=$ luas penampang

$\mathrm{Q}=$ debit air $\left(\mathrm{m}^{3} / \mathrm{s}\right)$

Pengukuran debit air secara langsung dilakukan dengan menggunakan sekat ukur. Sedangkan pengukuran debit air secara tidak langsung dilakukan dengan cara menentukan rata-rata luas penampang basah saluran dikalikan dengan kecepatan aliran air rata-rata. Pengukuran secara tidak langsung inilah yang banyak digunakan oleh para pembudidaya ikan dilapangan karena relatif mudah dilakukan. Fluida sebagai medan rapat massa dan medan vektor kecepatan. Tiap besaran yang dipergunakan untuk menyatakan keadaan fluida akan mempunyai nilai tertentu pada tiap titik dalam ruang dan pada tiap saat.

Prosedur yang tepat dan singkat dalam pengambilan keputusan oleh pengambil kebaijakan dalam penentuan daerah bahaya untuk pemukiman dan daerah persawahan serta ladang. Salah satu jawaban untuk mengetahui kecepatan dan keringgian air menggunakan peringatan dini. Model peringatan dini yang efektif dan efisien sangatlah dibutuhkan. 
Situasi Daerah Desa Sade merupakan daerah bukit, lereng dan pegunungan dengan dan ada mempunyai kelerengan lebih dari 20 derajat, lapisan lapisan tanah tebal diatas leren, terdapat sistem tata air dan tata guna lahan yang buruk, lereng terbuka atau gundul akibat penebangan pohon secara brutal, adanya retakan pada bagian atas tebing, terdapat mata air atau rembesan air pada tebing yang disertai dengan longsoran kecil, pembebanan yang berlebihan pada lereng seperti adanya bangunan rumah atau sarana lainnya. Untuk pada gambar 2. merupakan gambar untuk konsisi tempat pelaksanan yang akan dilakukan di Desa Sade dengan kondisi alam areal perbukitan sedangkan untuk posisi Desa Sade.

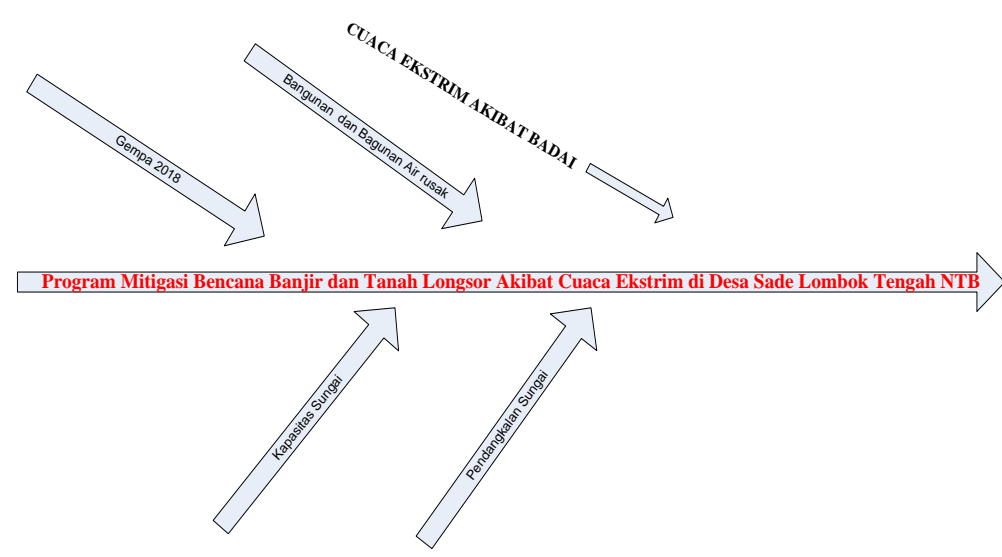

Gambar 1. Alur Pelaksanaan Pengabdian

\section{HASIL DAN PEMBAHASAN}

Hasil penelitian dari group riset sudah banyak dipublikasikan baik diteingkat nasional maupun internasional. Metode yang digunakan adalah pemaparan hasil riset dan kejadian aktual saat ini. Pembuatan peta mitigasi akan memperoleh informasi untuk jalur penyelamatan diri pada keadaan gempa dan sesudah gempa.

Pengabdian dilaksanakan dengan sistem gabungan antara online dan offline melibatkan Dosen Alumni dan Mahasiswa Teknik elektro. Pengabdian dilaksanakan dengan melibatkan 4 mahasiswa dan Alumni yaitu : Suci Raditya (2020), Alfin(2019), dan alumni Kenya(2015), dan Isfa (2015).

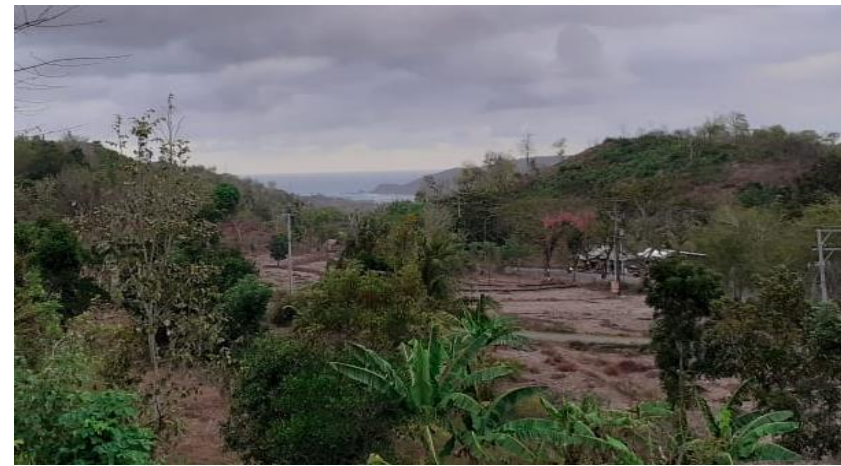

Gambar 2 Gambaran dari atas Daerah di Desa Sade 

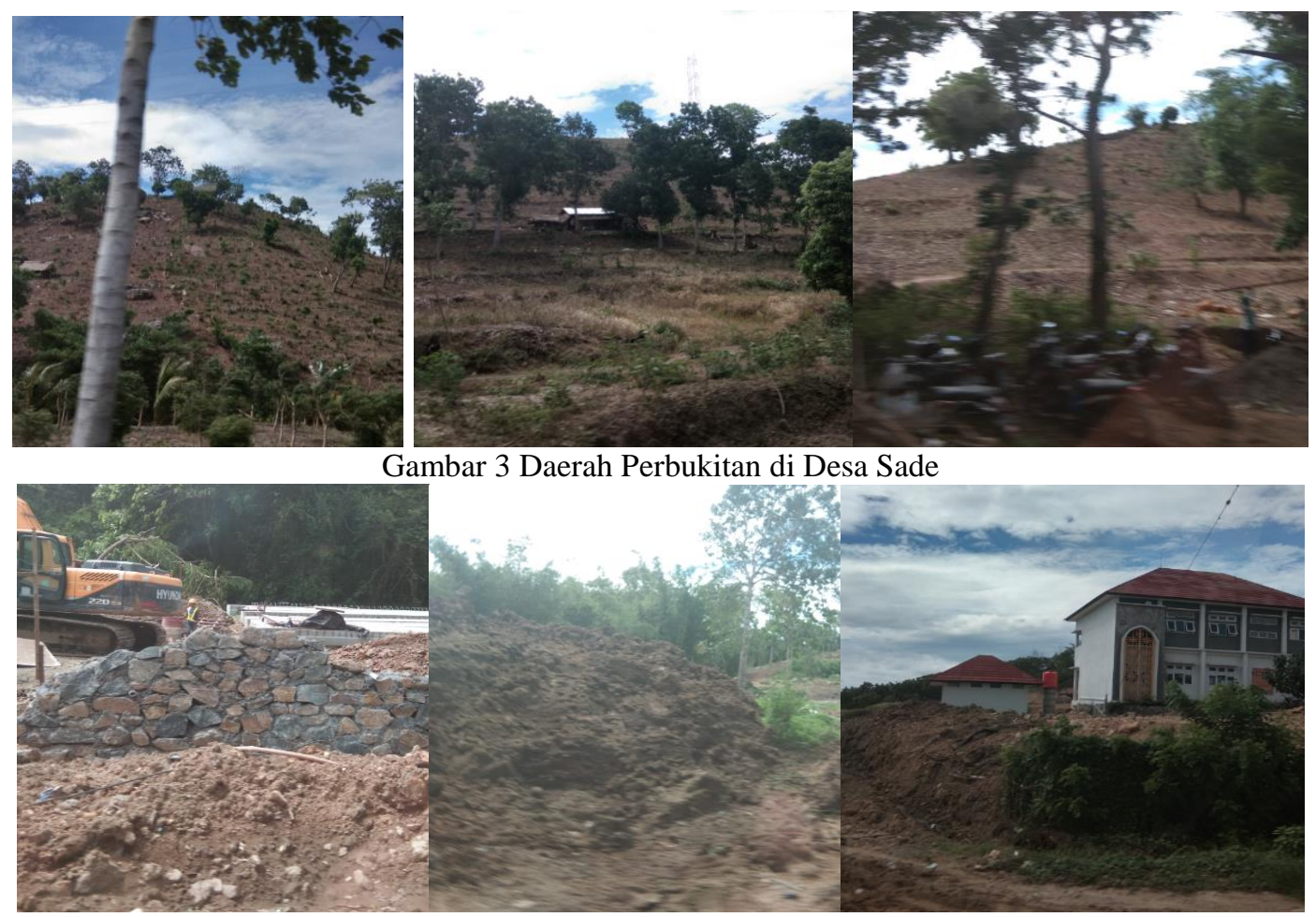

Gambar 4 Kondisi Perbaikan Setelah Cuaca Ekstrim.

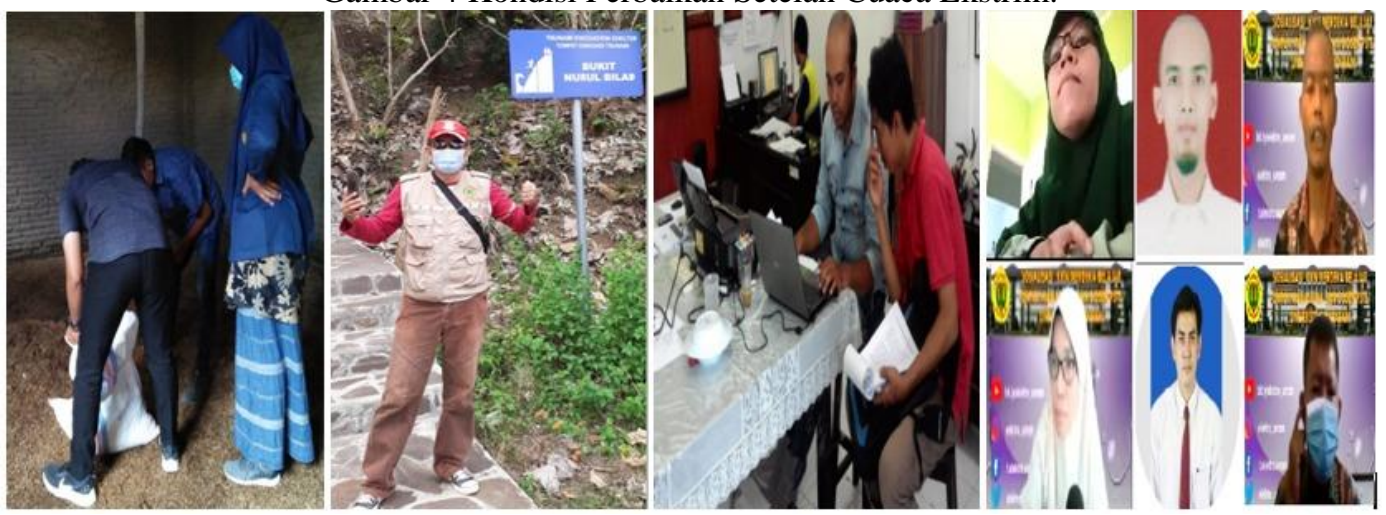

Gambar 5 Pelaksanaan Kegiatan Pengabdian secara online dan offline

Kegiatan dilaksanakan dengan memberikan sosialaisasi tanggap bencana dengan kondisi cuaca ekstrim (dengan badai). Kondisi badai pada masa kedepan kemungkinan datang lagi karena pertumbuhan badai siklon yang terjadi Bulan Januari 2021 tumbuh di Laut Banda. Ini menyebabkan ekor dari badai tersebut sampai ke NTB menyebabkan banjir dan tanah longsor.

\section{KESIMPULAN DAN SARAN}

Pelaksanan sosialisasi terhadap banjir dan tanah longsor perlu secara intens dilaksanakan untuk tepap waspada pada daerah kemiringan dan tidak ada pepohonan yang kuat mengikat tanah. Curah hujan tinggi dalam waktu lama dan tidak mempunyai saluran irigasi yang baik dapat menyebabkan banjir, yang paling mengerikan bila terjadi banjir bandang (banjir yag disertai tanah longsor). Kesiap siagaan dalam menggadapi bencana tersebut harus secara dini disosilisasi dengan 
baik. Tugas dosen melaksanakan Tri Dharma Perguruan Tinggi untuk mengabdi pada masyarakat dapat bersinergi dalam melaksanakan kegiatan ini, serta kalangan praktisi dan BPBD sebagai peneliti dapat bersatu untuk membatu masyarakat sebagai kepedulian dan penerapan hasil penelitian yang telah dilakukan untuk keselamatan umat manusia terhadap bahaya dan resiko terjadainya bencana alam yaitu banjir dan tanah longsor.

\section{Ucapan Terima Kasih}

Terima kasih diucapkan kepada semua mahasiswa dan Alumni PUI Geomagnetik dan EMTECH Teknik Elektro Universitas Mataram yang menyukseskan mendokumentasikan kegiatan, serta semua yang tidak disebutkan satu persatu dalam membantu dan menfasilitasi peyelesaian makalah ini. Pembiayaan untuk publikasi ini sepenuhnya menggunakan dana DPP/SPP Teknik Elektro dan setoran setiap anggota Pengabdian pada Masyarakat. Semoga makalah ini dapat inspirassi dari kegiatankegiatan selanjutnya.

\section{DAFTAR PUSTAKA}

BPBD 2021," bpbd.go.id" Situs BPBD diakses pada tanggal 27 Februari 2021

Riza Rahardiawan dan Catur Purwanto 2014, "Struktur Geologi Laut Flores, NUSA TENGGARA TIMUR NTT “, Jurnal Geologi Kelautan Volume 12 edisi April 2014

Yadnya MS., I.W. Sudiarta, 2010 "Neuro-Fuzzy ARMA Modeling from Rain Rate Measurement to Simulation Modeling for Earlywarning System in Mataram. ICAST 2020

Yadnya MS., I.W. Sudiarta, 2016 "Measurement of Drop Size Distribution Rain in Mataram Utilize Disdrometer Acoustic For Floods Prediction. SITIA 2016 (IEEE Xplore Indexed)

Yadnya MS., Zubaidah T, Paniran, Zaenuddin A, Bulkis K. 2019 "Sosialisasi Pengukuran Obsevatorium Rembutan dan Nurul Bayan Untuk Anomali Magnet Bumi Prediksi Gempa Bumi Pulau Lombok", Proseding Seminar Nasional Pepadu I Universitas Mataram NTB Indonesia.

Yadnya MS., Zubaidah T, Paniran, Zaenuddin A, Bulkis K. 2020 "PROGRAM SEKOLAH SIAGA BENCANA GEMPA BUMI DAN TSUNAMI DI PAUD PONPES NURUL WATHAN LOMBOK TENGAH”, Proseding Seminar Nasional Pepadu II Universitas Mataram NTB Indonesia

Yadnya MS., Zubaidah T, Paniran, Zaenuddin A, Bulkis K. 2020 "Program Penerapan Mitigasi Bencana Gempa Bumi Di Ponpes Nurul Wathan Lombok Tengah NTB Berorientasi Pada Penurunan Magnet Bumi Akibat Pergerakan Sesar Patahan”, Jurnal Gema Ngabdi 2 (3), 211-215, Universitas Mataram NTB Indonesia

Yadnya MS, I.W. Sudiarta, W. Wedashwara 2021. "Classification of location landslides areas with direct measurement and remote in Central Lombok", pp 252-256, ICST 2020 University of Mataram NTB Indonesia.

Zubaidah T, Misbahuddin, Kanata B, Paniran, Rosmaliati, Yadnya MS, Riskia S (2018) "Earth Magnetic Fields Evolution over Nusa Tenggara Region from Declination and Inclination Changes on Lombok Geomagnetic Observatory", The $2^{\text {nd }}$ International Conference on Applied Electromagnetic Technology (AEMT) 2018, Engineering Faculty of University of Mataram, Lombok. (IEEE Xplore Indexed). 